\title{
Incomplete Implant Insertion Due to the Use of A Non-dynamometric Torque Wrench: A Case Report
}

\author{
Jesús M. González-González
}

\author{
Doctor of Medicine and Surgery (University of Alicante). Specialist in Stomatology \\ (University of Murcia). Practice in a Private Dental Clinic, in Salamanca (Spain)
}

*Corresponding Author details: Jesús M. González-González; gongonjm@hotmail.com

\begin{abstract}
A case is reported in which the use of a non- dynamometric torque wrench could be the cause of incomplete implant insertion. A woman, 73-year-old, visited the dentist in March 2021 for oral rehabilitation due to the absence of teeth in the left mandibular area. A Galimplant IPX 4.5 x 8 implant (internal hex connection) (Sarria, Spain) was placed in position 36. Bone drilling was performed correctly in width and depth, however, insertion of the implant was difficult due to the hardness of the cortical bone. New drillings were made in the bone with insertion and removal of the implant on three occasions. On the third occasion, the implant was threaded to a depth of $7 \mathrm{~mm}$. At that time, the thread that the implant had carved in the bone had been lost and the implant did not advance until $8 \mathrm{~mm}$ in depth, nor could it go back to remove it and continue drilling the bone. We estimate that a dynamometric torque wrench should have been used during implant insertion, to provide adequate torque and not cause the loss of the thread that the implant had carved into the bone. The use of a non-dynamometric torque wrench does not allow a precise insertion torque. If excessive torque is applied, the thread carved by the implant in the bone can be lost and this finally causes an incomplete insertion of the same.
\end{abstract}

Keywords: non-dynamometric torque wrench; dynamometric torque wrench; implant; complication.

\section{INTRODUCTION}

Implant insertion success differs from site to site and patient to patient, but depends on the material, biocompatibility, implant design, patient factors, tissue health, bone quality and quantity, issues of the procedure such as insertion torque, load moment, duration of healing, biomechanical load and prosthetic design [1,2].

The force used to insert a dental implant is called the "insertion torque" and is expressed in $\mathrm{Ncm}$ (Newton centimeter). Factors that affect the insertion torque are bone density and hardness, the use of insufficiently sized drills, and the design of the conical implant. Torque is directly proportional to bone density (type D- 1 bone is the highest and type D-4 is the lowest) [2]. Some authors point out that there is no established minimum torque to be used to achieve the primary stability of the implant. Forces $>=30 \mathrm{Ncm}$ are usually used. If an increased torque is used ( $>=50 \mathrm{Ncm}$ ) there is more stability, which reduces micromovement and this facilitates osseointegration without damaging the bone. The healing process is similar if the insertion torque is high or low [3]. It has been pointed out that there is no significant difference between implants inserted with high $(>25-176 \mathrm{Ncm})$ or low $(<30-35 \mathrm{Ncm})$ insertion torque values concerning the marginal bone resorption [4]. When implants with torque $<10 \mathrm{Ncm}$ and $30 \mathrm{Ncm}$ were compared, greater osseointegration was seen in implants with a torque of $30 \mathrm{Ncm}$, but those with torque $<10 \mathrm{Ncm}$ also had good osseointegration [5]. A similar result was obtained when comparing implants inserted with low $(<10 \mathrm{Ncm})$ and high ( $>50 \mathrm{Ncm}$ ) torque. In both cases, they have good osseointegration [6].
However, it is thought that high torques can alter angiogenesis and the formation of new blood vessels. This would cause hypoxia in peri-implant tissues, which inhibits bone formation and this affects stability [2]. For this reason, it is advisable not to exceed torques of $50 \mathrm{Ncm}$. For the immediate loading protocol, the torque of $35 \mathrm{Ncm}$ is considered optimal, although the range of insertion torques can vary from $15-150 \mathrm{Ncm}$ [2]. High insertion torques (110 $\mathrm{Ncm}$ ) do not cause bone necrosis and high torque is important to increase primary stability and for the immediate loading protocol [2]. We have not found any bibliography that refers to the non-dynamometric torque wrench as a cause of complications. A case is reported in which the use of a non- dynamometric torque wrench could be the cause of incomplete implant insertion.

\section{CASE REPORT}

This report presents a case of a woman, 73-year-old, who visited the dentist in March 2021 to oral rehabilitation due to the absence of teeth in the left mandibular area. For this reason, an orthopantomography was requested (fig1).

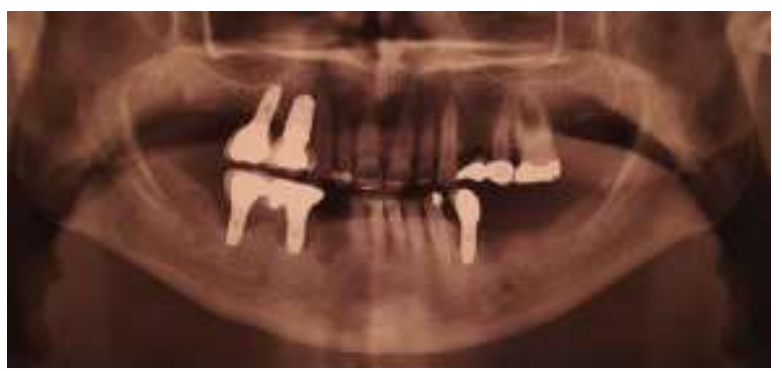

FIGURE 1: Orthopantomography before treatment. 


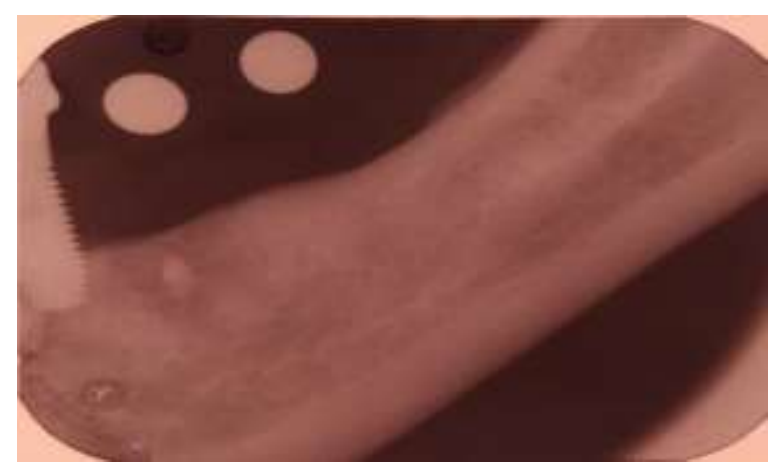

FIGURE 2: Periapical radiograph with $4 \mathrm{~mm}$ metal reference balls.

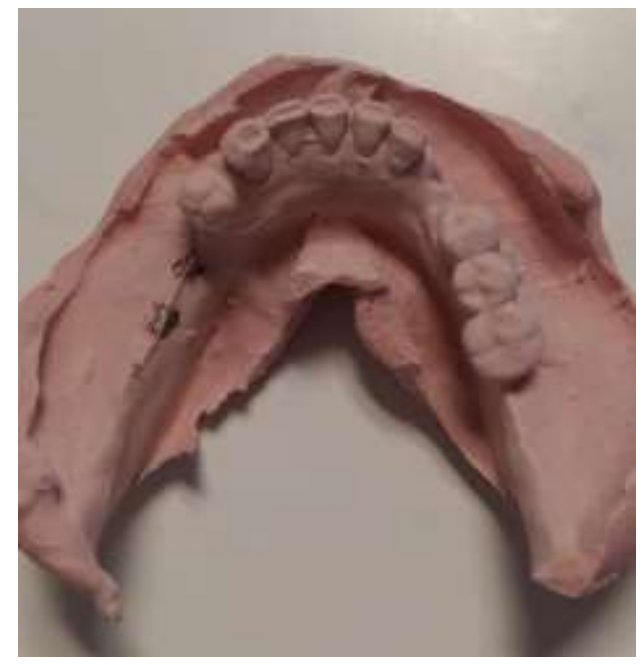

FIGURE 3: Lower model of the mouth in plaster.

Implant 34 was stable although it had bone loss, so it was decided to keep it. It was planned to insert implants in positions 35 and 36 with a delayed technique in the placement of the fixed prosthesis. Four periapical radiographs of the area were also taken from different angles (fig. 2) and a lower model of the mouth in plaster (fig. 3 ). Days before surgery, the entire procedure (oral and written) was explained to the patient, written informed consent was taken and antibiotic (amoxicillin/ac. clavulanate 500/125, every 8 hours) was recommended for prevention. On the day of surgery, a simple opening flap was performed, drills were used sequentially and a Galimplant IPX 4 x 10 implant (internal hex connection) (Sarria, Spain) was placed in position 35. A non-dynamometric torque wrench was used for its insertion, obtaining good primary stability. Then another Galimplant IPX 4.5 x 8 implant (internal hex connection) (Sarria, Spain) was placed in position 36, the data of which we will highlight below. Bone drilling was performed correctly in width and depth, however, insertion of the implant was difficult due to the hardness of the cortical bone. New drillings were made in the bone with insertion and removal of the implant on three occasions. On the third occasion, the implant was threaded to a depth of $7 \mathrm{~mm}$. At that time, the dentist thought that with one more turn with the non-dynamometric torque wrench, the implant would be inserted at $8 \mathrm{~mm}$ as planned, however, it did not exceed $7 \mathrm{~mm}$. At that time, the thread that the implant had carved in the bone had been lost and the implant did not advance until $8 \mathrm{~mm}$ in depth, nor could it go back to remove it and continue drilling the bone. In other words, the implant rotated to one side and the other, with a good grip, but without going deeper into the bone, nor that it could be removed from it. There was no longer the possibility of re-drilling the bone to try to insert the implant deeper and as the stability achieved was good, the dentist decided to leave it in that position and it was closed with a non-absorbable suture (FIGURE 4).
The next day the patient had mild discomfort and swelling. In a review carried out a week later, she was already well.

\section{DICUSSION}

In dental implantology, there may be mechanical complications such as prosthesis screw loosening or fracture, porcelain or resin fracture, abutment screw loosening or fracture, and implant fracture [7-9]. This is due to material fatigue and/or corrosion [10], or due to lack of passive adaptation between the prosthesis and the implant. There may also be clinical complications of vascular type, nervous type, or invasion of the maxillary sinus [11-13]. Incomplete implant insertion is not a complication, but an unplanned inconvenience.

In FIGURE 5 we have five types of torque wrench to insert implants in the bone. With the non-dynamometric torque wrench (fig. 5a) there is no possibility of calculating the correct force to apply. It all depends on the experience of the dentist. In the case described, the dentist used that nondynamometric torque wrench (fig. 5a) as it was the one that best suited the implant fixture mount. If the implant is not inserted into the bone with desired depth and pressure, it is possible to remove it, re-drill the bone and insert it again. And this as many times as necessary until it is in the correct position planned. In the case described, this was done on three occasions, but on the third, the implant could not be removed by doing reverse torque. The implant remained in the bone and rotated within it as if it had lost its thread. We believe this is due to the use of the non-dynamometric torque wrench. When the implant in position 36 had depths up to $7 \mathrm{~mm}$, the dentist thought that one more turn of the non-dynamometric torque wrench would be enough to get it to $8 \mathrm{~mm}$, but it was not. By not being able to calculate the force made with that non-dynamometric torque wrench, the dentist could have made an inappropriate force to reach those $8 \mathrm{~mm}$ of depth. At that time, the thread that the implant had carved into the bone was lost and it turns to one side and the other without advancing in depth, and neither could it be removed with reverse torque. However, the stability was good.

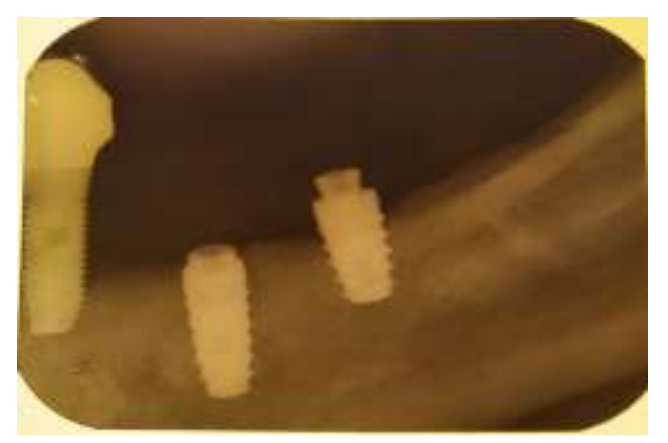

FIGURE 4: Galimplant IPX 4 x 10 and 4.5 x 8 implants in positions 35 and 36 respectively.

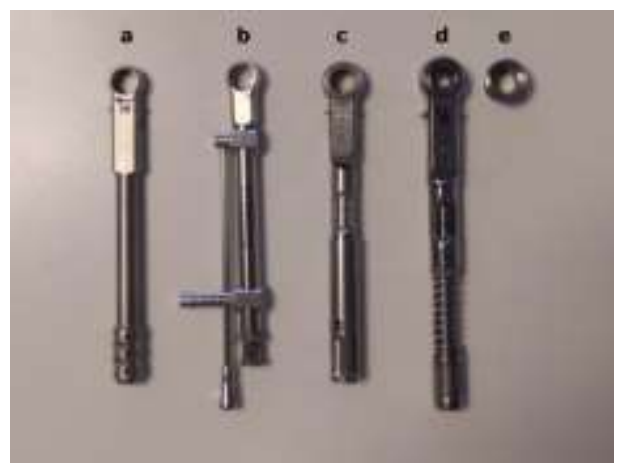

FIGURE 5: Different types of torque wrenches. Non-dynamometric (a) and dynamometric (b, c, d, e). 
According to previous authors, the torque range to apply is $15-150 \mathrm{Ncm}$, but this is a very wide range. Between 30-50 $\mathrm{Ncm}$ has been estimated as the most suitable, with $35 \mathrm{Ncm}$ being the most optimal [2]. Torques higher than that can cause loss of the thread that the implant has carved into the bone. This causes the implant to rotate, but without advancing deep into the bone. With a non-dynamometric torque wrench, it is impossible to calculate whether the applied torque force is optimal. The mechanical resistance to the extraction of implants can vary depending on the type of bone or the substrate where they have been inserted $[14,15]$. It has been described that when the implants are left to integrate for 3 months (for the 2nd stage of surgery) if at that time $30 \mathrm{Ncm}$ of reverse torque is applied and it does not move, it means that there is good osseointegration [16]. In the case described, with the non-dynamometric torque wrench it is not possible to calculate the amount of reverse torque applied. The implant was moving, but could not be removed. According to the authors, the minimum force that is done with digital torque (with the fingers) is between $2.18+/-1.05 \mathrm{Ncm}$ and $7.51+/-2.52 \mathrm{Ncm}$ [17]. The digital torque is as inaccurate as the non-dynamometric torque wrench. As the implant described did not move with the fingers, it must be considered that this implant was inserted with a torque greater than $10 \mathrm{Ncm}$.

We estimate that a dynamometric torque wrench should have been used during implant insertion (fig5, b-e), to provide adequate torque and not cause the loss of the thread that the implant had carved into the bone.

\section{CONCLUSION}

The use of a non-dynamometric torque wrench does not allow a precise insertion torque. If excessive torque is applied, the thread carved by the implant in the bone can be lost and this finally causes an incomplete insertion of the same.

\section{REFERENCES}

[1] C. Concejo Cútoli, N. Montesdeoca García.Carga inmediata en implantes dentales.Immediate loading of dental implants. Rev Esp Cirug Oral y Maxilofac. $2005 ; 27(5): 255-269$

[2] Venkatakrishnan C. J, Bhuminathan S, Chandran C. R. Dental Implant Insertion Torque and Bone Density Short Review. Biomed Pharmacol J. 2017; 10(3): 1305-1309.

[3] Gary Greenstein, John Cavallaro. Implant Insertion Torque: Its Role in Achieving Primary Stability of Restorable Dental Implants. Compend Contin Educ Dent. 2017; 38(2):88-95.

[4] Marco Berardini, Paolo Trisi, Bruna Sinjari, Anne W S Rutjes, Sergio Caputi. The Effects of High Insertion Torque Versus Low Insertion Torque on Marginal Bone Resorption and Implant Failure Rates: A Systematic Review With Meta-Analyses. Implant Dent. 2016; 25(4):532-40.

[5] Yoshiyuki Amari, Adriano Piattelli, Karol Alí Apaza Alccayhuaman, Natalia Fortich Mesa, Mauro Ferri, Giovanna Iezzi, Daniele Botticelli. Bone healing at non-submerged implants installed with different insertion torques: a split-mouth histomorphometric randomized controlled trial. Int J Implant Dent. 2019; 5(1):39. doi: 10.1186/s40729-019-0194-2.

[6] Joke Duyck, Rutger Roesems, Marcio V Cardoso, Toru Ogawa, Germana De Villa Camargos, Katleen Vandamme. Effect of insertion torque on titanium implant osseointegration: an animal experimental study. Clin Oral Implants Res. 2015; 26(2):191-6.
[7] Alejandra Recio Sánchez (2018). Complicaciones biomecánicas de los implantes: fractura y aflojamiento de tornillos. Trabajo fin de grado. Facultad de odontología. Universidad de Sevilla, Sevilla.

[8] Yamile El Ghannam Ruisánchez, José Manuel Valdés Reyes, Clara Sánchez Silot. Complicaciones Mecánicas en Implantes Dentales unitarios de carga diferida. Revista Europea de Odontoestomatología, 2015. (Accessed november 2, 2020 at http://www.redoe.com/ver.php?id=178).

[9] Johannes Schmitt, Stefan Holst, Stephan Eitner, Andreas Schlegel, Manfred Wichmann, Jörg Hamel. Valores de torque de desinserción de los tornillos protésicos en implantes fijados a supraestructuras de barras modelo o barras modificadas según la técnica de precisión Cresco Ti: estudio comparativo in vivo. Revista Internacional de Prótesis Estomatológica. 2010; 12 (1): 23-30.

[10] Ángel Orión Salgado-Peralvo, Ahmad Haidar Wehbe, Alvaro García Sánchez, Nuno Matos Garrido, Iván Ortiz García, Eugenio Velasco Ortega. Factores de riesgo en implantología oral. Revisión de la literatura. Revista Española Odontoestomatológica de Implantes. 2018; 21 (1): 1-8.

[11] Pablo Galindo, Elena Sánchez-Fernández, Gustavo Avila, Antonio Cutando, Juan Emilio Fernandez. Migration of implants into the maxillary sinus: two clinical cases. Int J Oral Maxillofac Implants. 2005; 20(2):291-5.

[12] Jun-Hyeong An, Sang-Hoon Park, Jeong Joon Han, Seunggon Jung, Min-Suk Kook, Hong-Ju Park, HeeKyun Oh. Treatment of dental implant displacement into the maxillary sinus. Maxillofac Plast Reconstr Surg. 2017; 39(1):35.

[13] Gallego Medina I, Sánchez Garcés Ma A, Berini Aytés L, Gay Escoda C. Desplazamiento de un implante dental dentro del seno maxilar durante la segunda fase quirúrgica. Av Periodon Implantol. 2002; 14,2: 81-88.

[14] Nathalia Ferraz Oliscovicz, Antônio Carlos Shimano, Elcio Marcantonio Junior, César Penazzo Lepri, Andréa Candido Dos Reis. Analysis of primary stability of dental implants inserted in different substrates using the pullout test and insertion torque. Int J Dent. 2013: 194987. doi: $10.1155 / 2013 / 194987$.

[15] Martínez-González JM, García-Sabán F, FerrándizBernal J, Gonzalo-Lafuente JC, Cano-Sánchez J, Barona-Dorado C. Removal torque and physicochemical characteristics of dental implants etched with hydrofluoric and nitric acid. An experimental study in Beagle dogs. Med Oral Patol Oral Cir Bucal. 2006; 11:281-5.

[16] Sabrina G Simeone, María Rios, Jeannette Simonpietri. "Reverse torque of $30 \mathrm{Ncm}$ applied to dental implants as test for osseointegration"-a human observational study. Int J Implant Dent. 2016; 2(1):26. doi: 10.1186/s40729-016-0060-4.

[17] André Antonio Pelegrine, Fabíola Mayumi Miyauchi Kubo, Débora Barella Salatti, Marcelo Lucchesi Teixeira, Alireza Moshaverinia, Peter Karyen Moy. Can Finger-Generated Force Be Used Reliably to Connect the Transducer for Resonance Frequency Analysis in Determining Implant Stability? Int J Oral Maxillofac Implants. 2020; 35(6):1141-1148. 